\title{
True Radial Artery Aneurysm Presenting With Behçet's Disease
}

\author{
Serkan Burç DEŞER, Mustafa Kemal DEMİRAĞ \\ Department of Cardiovascular Surgery, Medical Faculty of Ondokuz Mayıs University, Samsun, Turkey
}

Iatrogenic (cannulation), penetrating trauma, vascular tumors, connective tissue diseases, and Behçet's disease $(\mathrm{BD})$ are the main etiological factors for true radial artery aneurysms (RAA). The prevalence of RAA is $2.9 \%$, which is the rarest in upper limb aneurysms. ${ }^{1}$ RAA may present as pulsatile swelling with or without pain, distal ischemia, spontaneous rupture, and thrombosis. BD is also a systemic vasculitis which is mostly seen in Mediterranean, Middle East, and Japan and commonly in young males. ${ }^{1}$ Panvasculitis (vasculitis of the vasa vasorum with the infiltration of the perivascular lymphocytes) and fibrosis are determined by histopathological examination. ${ }^{1}$ Major manifestations of vascular $\mathrm{BD}$ are venous occlusion, arterial occlusion, and rapidly expanding aneurysms formation. Arterial association including both aneurysm and occlusion is about $7 \%{ }^{2}$ However, arterial occlusions are seen more often than the aneurysms. ${ }^{2}$

In this article, we present our experience in the coexistence of RAA with BD. A 25-yearold male patient was referred to our hospital with pain and mass on his right thigh. Patient had history of bilateral deep venous thrombosis and taking anticoagulant medication. His physical examination revealed a pulsatile mass at his left wrist concurrently. The lesion had rapidly increased in size in a couple of weeks. Radial and ulnar pulses were present. Positive Allen's test showed domination of the ulnar supply to the palmar arch. A Doppler ultrasound revealed $10 \times 12 \mathrm{~cm}$ hematoma in his right thigh, acute thrombosis in his right common femoral vein, and true saccular RAA. Routine preparation for surgery was made and a written informed consent was obtained from the patient. Under local anesthesia, the aneurysm site was incised. A $2 \times 2 \mathrm{~cm}$ saccular aneurysm was excised at the distal part of the radial artery (Figure 1). The histopathological report showed clusters of lymphocytes neutrophils, plasma cells, fibrin infiltration, and destruction in the intima and medial layer of the arterial wall. The postoperative course was uneventful and he was discharged with oral anticoagulation and oral prednisolone at $25 \mathrm{mg}$ twice daily.

The initial diagnosis can be made clinically. Duplex ultrasound, and computed tomography and magnetic resonance angiographies can also be used for diagnosis. Digital subtraction angiography is not recommended due to its invasive nature which may lead to new pseudoaneurysm on the puncture site. Arterial ligation, excision of the aneurysmal sac or arterial reconstruction (end to end or graft interposition) are the surgical treatment options. Aggressive immunosuppressive therapy may prevent complications such as recurrent anastomotic, puncture site pseudoaneurysm formation in patients with BD. ${ }^{3}$ Endovascular treatment stent placement is not recommended

Received: July 24, 2016 Accepted: July 31, 2016 Published online: January 18, 2017

Correspondence: Serkan Burç Deşer, MD. Ondokuz Mayıs Üniversitesi Tıp Fakültesi Kalp ve Damar Cerrahisi Anabilim Dalı, 55105 Samsun, Turkey.

Tel: +90 362 - 3121919 e-mail: sbd983@yahoo.com

○2017 Turkish League Against Rheumatism. All rights reserved. 

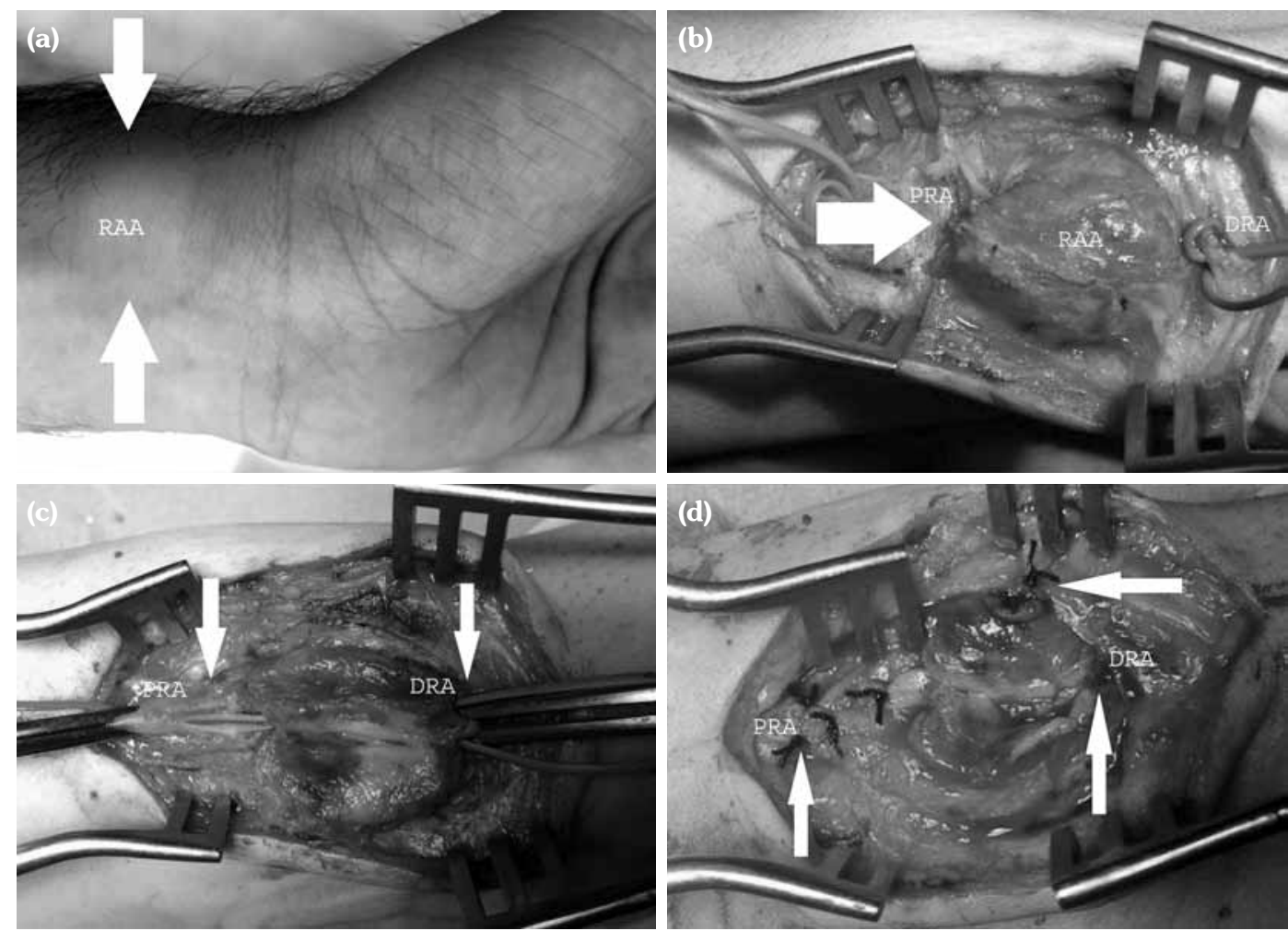

Figure 1. (a) External view of left radial artery aneurysm. (b) Intraoperative view of thrombosed radial artery aneurysm. (c) Exclusion of radial artery aneurysm. (d) Ligation of proximal radial artery and distal radial artery.

in patients with $\mathrm{BD}$, which may result in new pseudoaneurysms both on puncture site and on the aneurysm sac due to metallic hooks of the stent penetrating into the aortic wall.

In conclusion, surgery is still the gold standard treatment method in patients with RAA with $\mathrm{BD}$. In our patient, we excised the aneurysmal sac and ligated the radial artery due to the positive Allen's test that confirmed the ulnar artery dominancy and findings of intraoperative Doppler ultrasound.

\section{Declaration of conflicting interests}

The authors declared no conflicts of interest with respect to the authorship and/or publication of this article.

\section{Funding}

The authors received no financial support for the research and/or authorship of this article.

\section{REFERENCES}

1. Koksoy C, Gyedu A, Alacayir I, Bengisun U, Uncu H, Anadol E. Surgical treatment of peripheral aneurysms in patients with Behcet's disease. Eur J Vasc Endovasc Surg 2011;42:525-30.

2. Yaghoubian A, de Virgilio C. Noniatrogenic aneurysm of the distal radial artery: a case report. Ann Vasc Sur 2006;20:784-6.

3. Hassikou H, Bono W, Bahiri R, Abir S, Benomar M, Hassouni NH. Vascular involvement in Behçet's disease. Two case reports. Joint Bone Spine 2002;69:416-8. 